\title{
Will We See Helping Hands? Predicting Civil War Mediation and Likely Success
}

\author{
Govinda Clayton, Conflict Analysis Research Centre, University of Kent, \\ Kristian Skrede Gleditsch, University of Essex \& Peace Research Institute Oslo (PRIO)
}

\begin{abstract}
We examine whether features highlighted as important for mediation in existing research allow us to predict when we will see mediation and likely success out-of-sample. We assess to what extent information about the characteristics of the conflicting dyads and conflict history can be evaluated ex ante and improve our ability to predict when conflicts will see mediation as well as when peaceful solutions are more likely to follow from mediation. We justify that the information used to generate predictions through the model can be assessed ex ante, using the ongoing conflict in Syria as an example. Our results suggest that a two stage model of mediation and success seems to do relatively well overall in predicting when mediation is likely to occur, but notably less well in predicting the outcome of mediation. This may reflect how ex ante observable structural characteristics are likely to influence willingness to mediate, while the outcome of mediation to a large extent will be influenced by unobservable characteristics or private information and how these are influenced by mediation. We discuss the usefulness of out-of-sample evaluation in studying conflict management and suggest future directions for improving our ability to forecast mediation.
\end{abstract}

Key Words: Civil Conflict, Mediation, Conflict Management, Prediction, Forecasting.

Citation: Clayton, G. \& Kristian Skrede Gleditsch. 2014. 'Will We See Helping Hands? Predicting the Onset and Outcome of Civil War Mediation' Conflict Management and Peace Science. Forthcoming. (with Kristian Skrede Gleditsch).

BioNote: GOVINDA CLAYTON, b. 1983, PhD in International Conflict Analysis (University of Kent, 2013); Lecturer, School of Politics and International Relations and Deputy Director of the Conflict Analysis Research Centre, University of Kent (2010-).

KRISTIAN SKREDE GLEDITSCH, b. 1971, PhD in Political Science (University of Colorado, Boulder, 1999); Professor, Department of Government, University of Essex (2005- ) Research Associate, Centre for the Study of Civil War, PRIO (2003- ).

Acknowledgements: We are grateful to Kyle Beardsley, Han Dorussen, Sara M. T. Polo, Mauricio Rivera, Sebastian Schutte, Michael D. Ward, Glenn Palmer and four anonymous referees for helpful discussions and constructive comments. Gleditsch is grateful for financial support from the Research Council of Norway (180441/V10).

Data Statement: For replication data please email G.Clayton@kent.ac.uk

Corresponding author: G.Clayton@kent.ac.uk 


\section{Introduction}

Mediation is the most common form of intra-state conflict management (Bercovitch, Diehl and Goertz, 1997), and many accounts emphasize mediation as the most successful way for third parties to influence conflict (Dixon, 1996; Rauchhaus, 2006; Walter, 1997). A great deal of research has focused on developing propositions on when mediation is most likely as well as when it can help decrease the risk of further violence or escalation (Beardsley, 2008, 2009, 2010; Regan, 2010; Svensson, 2007, 2009). However, most research on mediation so far has exclusively evaluated hypotheses on mediation on observed (insample) data, and not considered to what extent existing research provides us with a basis for predicting the likelihood or outcome of mediation out-of-sample.

The neglect of out-of-sample forecasting in studies of mediation is unfortunate for a number of reasons. It is well known that hypothesis testing on observed data runs the risk of overfitting, or fitting to idiosyncracies of the specific sample rather than identifying stable structural relationships between a response and predictors (see Morgan and Henrion, 1990; Ward, Greenhill, and Bakke, 2010). Out-of-sample forecasting provides a complementary way to test hypotheses, using new information independent of the data used to develop the original hypotheses. Moreover, out-of-sample forecasting furthermore forces us to consider to what extent the suggested explanatory factors can be assessed ex ante by the decision makers involved in considering mediation, as opposed to features that are available to the researchers only ex post, or possibly endogenous to conflict processes or outcomes. This is a potential problem in existing research on mediation, particularly propositions stressing the characteristics of eventual mediators, which may not be known to the actors at the time. 
Beyond the value to the study of mediation, attention to conflict management can also help advance conflict forecasting by highlighting how third party efforts can increase or decrease the risk of escalation to violence and help foster alternative outcomes. Existing research on mediation often (implicitly or explicitly) offers some form of policy guidance, but these are generally grounded in significance tests on observed data rather than out-ofsample validation or predictive ability. In the context of civil war studies, Ward, Greenhill, and Bakke (2010) have recently warned of the perils of policy advice by $p$-values, without regard for the implied substantive effects that the estimates entail and the role of model uncertainty. By contrast, the ability to effectively forecast key aspects of conflict resolution could be of real relevance to conflict management efforts, and help identify the specific cases where conflict management is more likely to yield success and how to best invest scarce resources.

We extend previous research on mediation in civil war by assessing the predictive power of features highlighted as important determinants for mediation. In particular, existing studies have shown that mediation is more common in high stakes contest with significant insurgent threats to incumbents, thus increasing their interest in mediation (Clayton, 2013). As such, we expect more severe conflicts involving relatively strong rebels to be more likely to see mediation and an agreement resulting from mediation (Clayton, 2013; Cunningham, Gleditsch, and Salehyan, 2009). Moreover, previous conflict management has been shown to shape the likelihood of subsequent mediation attempts and their prospects of success, once the initial costs and hurdles such as rebel recognition have been overcome (see Bercovitch and Gartner, 2006). Finally, we examine whether ex ante observable information about the conflicting dyads characteristics and the conflict history can notably improve our ability to anticipate mediation efforts and when these succeed in managing violent conflict. 
We start with a brief review of forecasting in conflict analysis, before highlighting key recent findings in the study of mediation. We then propose a statistical model of mediation and examine its predictive ability applied to new data. We conclude by discussing how conflict management could be incorporated in future research on prediction as well as the value of out-of-sample evaluation in studying conflict management.

\section{Prediction and the Analysis of Conflict}

Prediction has always been an important aspiration for conflict research (see Choucri and Robinson, 1978; Singer and Wallace, 1979). The ability to reliably predict when interactions are likely to turn violent has obvious theoretical and practical interest, as demonstrated in the funding for prominent forecasting projects such as the Political Instability Task Force (e.g., Goldstone et al. 2010) and the widespread interest in various forecasting models for political events (see for example Bueno de Mesquita, 2002; O'Brien, 2010). A series of recent studies incorporate a number of new theoretical and methodological innovations within predictive studies of civil war (see Schneider, 2011). These studies consider key factors such as geography, ethnicity and location, using new geographic information systems (GIS) resources and data (see Rustad et al., 2011; Weidmann, Rød, and Cederman 2010), as well automated event data (see Brandt, 2011). It is increasingly common to report ex post and ex ante predictions in conflict research (Schneider, Gleditsch and Carey, 2011).

However, despite the expanding body of work focusing on predicting either initial conflict onset or escalation in violent conflicts, predicting conflict termination or the ability of external parties to induce settlements, and their effects on eventual outcomes out-ofsample remains untested. This poses two significant problems. Prediction to new data 
offers a stringent method for researchers to cross-validate findings (see Efron, 1983; Ward, Greenhill, and Bakke, 2010). Many empirical studies are based on a limited observed data and are often highly sample and model dependent. Prediction offers a way to evaluate the power and validity of models on new data. Such analyses can provide stronger support when models do well out of sample and identify limitations and possible avenues for improvement when models are less successful when applied to new data (see Ward, Greenhill, and Bakke, 2010).

The importance of model validation through prediction was recently highlighted by Ward, Greenhill, and Bakke (2010), who showed that the statistical significance for individual terms in statistical models of civil war is a poor indicator of their additional predictive power in out-of-sample forecasting. Their reexamination of the Collier and Hoeffler (2004) and Fearon and Laitin (2003) models indicated that only two variables (GDP per capita and population size) produced notable improvements in forecasting civil conflict onset. Schneider, Gleditsch and Carey (2011: 6) note how this should 'alert the research community to the need to assess whether their theoretically favored explanations really contribute to our understanding of why certain events have occurred and to the accurate prediction of a particular event in the future'.

In addition to advancing theory development and evaluation, developing forecasts for conflict termination and the impact of conflict management can also offer potentially significant benefits for policy and practice. Tetlock (2005) demonstrates through a series of over time studies that political experts tend to be excessively confident in their ability to predict future events. This in turn goes together with a problematic tendency to offer strong policy advice and recommendation, without much regard for the uncertainty over what we believe we know and what we can reliably anticipate about the future. As such, more systematic efforts to evaluate and improve our ability to forecast what cases are receptive 
to mediation and the likely added value of third party conflict management may help practitioners effectively allocate resources and prepare peace-building projects in anticipation of a settlement and avoid misplaced efforts.

\section{Modeling Mediation and the Effects of Mediation on Conflicts}

Research on civil war mediation has seen a notable growth in theory development and data. ${ }^{1}$ Much of the recent research in this area is informed by a bargaining framework, which suggests that belligerents in a conflict attempt to convey information about their capabilities and resolve in order to reach the best feasible agreements (see Fearon, 1995; Slantchev, 2003). From this perspective, mediation can assist disputants in overcoming information asymmetries and enhance the possibility of credible commitments to settle violent conflicts (see Beardsley et al., 2006; Walter, 1997; Wilkenfeld et al., 2005). This line of research has helped understand how, when and why mediation can work. However, empirical evaluations have generally been based upon observed, in-sample data, and research has not yet considered to what extent these insights allow us to forecast the likelihood or outcome of mediation, which we turn to in this article. We first briefly review the existing core theory that forms the basis for the model applied in our forecasting effort. We will discuss the rationale underpinning the specific propositions on mediation, but refer to the original research for a more complete description of the postulated mechanisms.

\footnotetext{
${ }^{1}$ For reviews of the development of the study of mediation, see Pruitt and Kressel (1989), Wall and Lynn (1993), Wall, Stark and Standifer (2001).
} 
The onset of mediation in a conflict hinges on both a third party being willing to offer their services and the belligerents being open to outside intervention. Mediation is a less costly form of involvement than economic sanctions or military action, and outside parties are often open to mediate (see Beardsley, 2009; Bercovitch and Schneider, 2000; Touval and Zartman, 1985). Supplying mediation can, however, incur significant costs for the intermediary, including administrative burdens, economic investment and reputational damage if the process collapses. Third parties are thus only likely to offer mediation when they (a) have some interest at stake in the resolution of war and (b) believe mediation will have a positive effect. Potential mediators are unlikely to invest scarce resources when they have no interest in the outcome or consider it unlikely that mediation will contribute to a better result.

Two countervailing forces have also been shown to shape demand for mediation. Incumbents are more likely to resist mediation since admitting a third party to a domestic conflict signals that a state is unable to control its territory and undermines its autonomy (see Clayton, 2013; Greig and Regan, 2008; Melin and Svensson, 2009). Conversely, rebels can gain legitimacy and status as a result of international engagement and thus tend to be more open to mediation (see Bercovitch and Jackson, 2001; Skjelsbæk, 1991; Svensson, 2007). From this perspective, scholars such Svensson (2007) and Regan and Greig (2008) argue that since states incur significant costs when they accept an intermediary, we should only expect mediation in costly and challenging contexts where the significant price of mediation is outweighed by high benefits of conflict resolution. In support of this, they have shown that mediation indeed is more likely in intense and long conflicts, where the price of continued conflict can be assumed to be high. Thus, we expect the dyadic relationship between the belligerents is likely to be a key observable predictor for the prospects for mediation. A relatively strong rebel movement will notably increase 
the costs of the status quo and make it harder for a government to continue fighting. Even if the rebels cannot win a conflict, they may be able to force the state to open for discussions if they pose a credible threat and can inflict sufficient costs (see Clayton, 2013; Greig and Regan, 2008).

Once in a dialogue process a strong rebel group can credibly commit to walk away from negotiations. Furthermore, rebel movements that can challenge the government military are better equipped to extract the commitment enhancing concessions that may be required for a settlement. Thus, the factors that strengthen the position of the rebels relative to the state should increase the likelihood of mediation and a successful outcome (Clayton, 2013). On the other hand, research modeling selection into and the outcome of mediation shows that although increased intensity and duration increase the likelihood of mediation, the resulting increase in complexity in a peace process can decrease the probability of a settlement (Svensson, 2007). Another body of work focusing on conflict management history has demonstrated how previous mediation attempts (in particular a history of successful outcomes) help bring about future mediation (see Bercovitch and Gartner, 2006; Regan and Greig, 2008). Moreover, conflicts in the post-Cold War period have been more likely to see mediation and more amenable to settlement (Regan and Greig, 2008).

Forecasting highlights the important distinctions between plausible ex ante observable characteristics and features that are only observable ex post, such as the characteristics of a specific mediator. The mechanisms and features discussed above can all be observed ex ante. For example, a decision maker interested in the prospects for mediation and the likely outcome can plausibly assess the strength of rebels relative to the state and whether a conflict has seen previous mediation attempts. By contrast, the features that have been stressed as important in research on mediation, such as the characteristics of mediators, can be assessed only once the mediator is known. Characteristics of mediators 
can obviously be important, but are unlikely to be helpful for out-of-sample forecasting of whether conflicts will be mediated unless likely mediators can be reliably identified in advance.

\section{Empirical Model and Analysis}

We develop a proposed model for mediation onset and outcome based on plausibly ex ante knowable features highlighted in previous research. Before turning to the model specification we first briefly discuss our approach to model training and out-of sampleprediction. We train the model on one observed subset of historical data and then generate predictions for a different body of data based on the training data coefficient estimates. This is not a true out-of-sample analysis since we use observed information on the right hand side covariates in generating predictions. ${ }^{2}$ However, the coefficients used to calculate the predictions are derived independently of the out-of-sample data, and we limit ourselves to covariates that can be observed ex ante, prior to mediation taking place. As such, we feel that this is a valid approach to evaluate to what extent existing research can help predict whether ongoing conflicts will see mediation and the prospects that such efforts will be successful.

${ }^{2}$ Strictly speaking a true out-of-sample forecast for mediation in conflict here would have to predict likely future conflicts and their relative likelihood of mediation and prospects for success, based on the likely characteristics of the conflicts. Our aim here is not to forecast conflict out of sample, but instead take the observed characteristics of conflicts that we see and evaluate the accuracy of our predictions for the likelihood of mediation and success based on the training data. 
We use the Civil War Mediation dataset (CWM, see DeRouen, Bercovitch \& Pospieszna, 2011) for information on mediation attempts and their outcomes. Many datasets examine mediation in interstate conflicts, but the CWM dataset is the first to focus on mediation in intra-state conflict. Based on the Uppsala Armed Conflict Termination data (see Kreutz, 2010), the CWM data detail civil war mediation in 317 episodes from 1946-2003 that meet the UCDP/PRIO definition of civil war, i.e. at least 25 battle deaths per year. Since there can be multiple mediation attempts over a conflict's lifespan, we separate conflict episodes into years, which yields a total of 1152 conflict years.

\section{Dependent Variables}

We identify whether mediation occurs within each of the individual conflict episode years. Following research on conflict onset, we drop mediation incidents that continue into the following year. For the outcome we use the CWM coding to construct a binary successful outcome indicator based on whether mediation is classified as achieving a process, partial or full settlement. This method of operationalizing mediation success obviously does not assess long-term effectiveness. The creation of a peace settlement does not always imply an end to violence, nor does it guarantee that a conflict will not reoccur. Recent research has suggested that even though mediation can help actors identify acceptable outcomes, the

artificial incentives created by mediation often result in less durable agreements than bilateral settlements (Beardsley, 2008; 2011). Still, to reach a peace settlement is a notable step towards peace and conflict resolution, and a significant achievement for a third-party mediator (see Bercovitch, 2007; DeRouen, Bercovitch \& Pospieszna, 2011; Jackson, 2000; Touval \& Zartman, 1985), so we see this as a valid indicator for at least one dimension of mediation success. 
For the training data, we use observations for the years 1946-1992. This spans 1112 conflict years, with 120 mediation onsets. We assess the forecast using observations for 1993-2003, which encompass 412 conflict years with 106 instances of mediation.

\section{Model}

Research on mediation argues that 'the occurrence of mediation, and the settlement should be modeled as two separate, but interlinked, questions' (Svensson, 2007: 253). A disputant's decision to accept mediation is likely to be closely connected to their expectations about likely success. Previous work has attempted to capture this through varieties of a two-stage selection model. However, selection models require strong identifying assumptions, and the conventional Heckman selection model is only appropriate when one can point to at least one additional explanatory factor that influences selection but not the outcome. In the absence of such an identifying restriction, the Heckman model estimates are 'based only upon ...the distributional assumptions about the residuals rather than the variation in the explanatory variables' (Sartori 2003:112).It is difficult to justify good distinct predictors for initial mediation selection and the eventual outcome of mediation, especially when focusing only on plausibly ex ante observable characteristics that actors may take into account before offering to mediate or accept mediation.

We instead use Sartori's (2003) alternative selection model estimator, which relies on the identifying assumption that the error term for an observation is the same in the selection and outcome equations. This is appropriate when the unmeasured factors influencing both selection and outcome can be assumed to have the same sign or direction. This seems reasonable here, as we would generally expect that unobserved variables that 
encourage states to accept mediation also increase the likelihood of success. ${ }^{3}$. For example, mediation is most likely when incumbents become more willing to compromise due to escalating costs of further war (see Beardsley, 2010; Greig, 2005; Greig \& Diehl, 2006). Since accepting an intermediary carries significant costs, the state is only then likely to accept mediation if its resolve has significantly diminished, for example through lower perceived prospects of victory or higher costs of conflict. This reduction in the unobservable 'resolve' is also likely to be strongly correlated with an increase in the probability of settlement.

\section{Predictors}

Given our focus on the ability to predict out-of-sample we consider only features consistently shown to exert an influence on strategic uncertainty in civil conflicts in the literature and that can be plausible assessed ex ante. We draw upon both contextual features that shape the conflict context and dyadic features that reflect the nature of the conflictual relationship. We here offer only a brief justification for the selection of each

${ }^{3}$ We acknowledge that there exists a contending view that belligerents will only accept mediation in challenging cases that they are unlikely to resolve alone, suggesting that mediation is more likely when the probability of success is low and a negative correlation between errors in the selection and outcome equation (see Gartner and Bercovitch, 2006). However, this argument ignores the costs incumbents suffer from mediation, which make it unlikely mediation will be accepted unless one expects a higher likelihood of settlement (see Clayton, 2013). 
variable, and refer to the original research for a more complete discussion of the postulated theoretical mechanisms.

We include a number of indicators of conflict characteristics that have frequently been linked to mediation attempts. First, we consider conflict intensity, since higher conflict costs raises the incumbent's willingness to accept mediation and settlement (see Clayton, 2013; Gartner and Bercovitch, 2006). Our intensity measure is a dummy variable indicating if a conflict crosses the 1,000 deaths per year threshold (see Lacina and Gleditsch, 2005). Second, we consider conflict duration or the number of years since conflict onset (Kreutz, 2010), since long conflicts typically involve small and weak insurgencies that are less likely to compel the state to accept mediation (see Bercovitch and DeRouen, 2004; Svensson, 2007). Third, we consider the nature of the incompatibility, flagging all conflicts fought over territorial incompatibilities where groups seek autonomy or secession as opposed to control over the government (see Kreutz, 2010). In particular, insurgents in territorial conflicts can often challenge the state in a specific area, even if clearly weaker than that the state outside the main the conflict zone. We thus expect territorial conflicts to be more likely to see mediation and settlement (Clayton, 2013). We also consider whether there are parallel conflicts within the state (Kreutz, 2010), since multiple insurgencies can increase the costs associated of mediation to the state. More specifically, if rewarding one insurgency can motivate other challengers to intensify their efforts, this increases the costs associated with mediation, which reduces the likelihood of dialogue and settlement (Cunningham, 2006; Walter, 2003). Finally, we include an indicator for whether a conflict occurred after the Cold War, since conflicts have been shown to be more likely to be mediated and terminate through peaceful means after 1989 (see Beardsley et al. 2006; DeRouen, Bercovitch and Pospieszna, 2011). 
We also consider a number of dyadic features, reflecting the relationship between belligerents. First we consider the relative strength of the insurgent force, since relatively stronger rebels are more likely to overcome barriers preventing conflict termination. Strong insurgents that can credibly threaten an incumbent are more likely to extract concessions from the state (Clayton, 2013; Cunningham, Gleditsch, and Salehyan, 2009). Thus, greater relative rebel strength should have a positive effect on both the onset and outcome of mediation. We use a three-point scale indicating whether rebels are weaker than the state (1), at parity with the state (2), or stronger than the state (3, see Cunningham, Gleditsch, and Salehyan, 2009). ${ }^{4}$

Finally, we consider conflict management history, since past conflict management efforts between belligerents increase the likelihood of future mediation success (Gartner and Bercovitch, 2006; Melin 2011). We include a variable recording whether a conflict saw mediation starting in the previous year (i.e., excluding mediation extending for more than one year). To account for the effect of previous mediation results we include an ordinal level variable coded 0 for no previous mediation, 1 if the process was unsuccessful, 2 for a ceasefire or process settlement, and 3 for a partial or full settlement. When mediation extends into the next calendar year we code the previous conflict management outcome as missing, since the eventual outcome of the process will not be known until later.

${ }^{4}$ We simplify the original five categories in the NSA dataset into this three point ordinal measure. Splitting the categories into separate dummy variables rather than treating the measure as interval does not lead to noticeably different results. 
We have argued that observers and decision makers can identify and evaluate the features included within our model prior to intervention. However, the data that we rely on has tended to be collected after events have taken place. To substantiate that this information actually is available ex ante, or can be identified in advance, we consider the ongoing conflict in Syria. ${ }^{5}$ We start with a brief review of the conflict, before identifying the assigned value of the covariates for the Syrian case.

Following previous political unrest in Tunisia, Egypt, and Libya, violence erupted in Syria on 15 March 2011. Around 150 people took to the streets to protest against the autocratic regime that has governed the state since 1970. The security forces responded in a heavy-handed manner, leading to an escalation in protest and violence. In May 2011, in response to the increasing threat against the state, the army deployed heavy artillery against the protestors. This quickly increased the casualties and the conflict escalated into a civil war as the opposition retaliated with violence. The intensity of the conflict continued to increase over the following months, and became a full scale civil war with more than 1000 deaths in early 2012 (BBC, 2012). As of June 2013, the United Nations has suggested that the death toll has risen to around 93,000, mainly on the non-government side, although government forces have suffered over 25,000 fatalities (BBC, 2013). In March 2012 the United Nations Special Representative Kofi Annan initiated the first mediation process in Syria, which produced a ceasefire and elements of a process agreement. However, the agreement quickly broke down, and the UN started a new mediation process, led by Lakhdar Brahimi.

${ }^{5}$ This conflict is on-going at the time of writing (July 2013). 
Table 1 presents our coding of the values for all covariates for the Syrian conflict at the start of the conflict in 2011. The Syrian conflict is clearly motivated by efforts to replace the ruling regime. Although the conflict originated outside the capital and may in part follow sectarian cleavages it is uncontroversial to classify this as an incompatibility over the government. Conflict duration is simple to determine when making predictions for mediation at any given time based on the onset date. Whether Syria is a single or multiple conflicts is more controversial, as the rebel movement in Syria is made up of a variety of different groups in different regions that at the outset of the conflict lacked a common command structure. However, a central leadership emerged under the Free Syrian Army, and we consider this case not to involve parallel conflicts. In terms of the relative strength of the rebel movement, at the time of writing the state forces struggle to contain the insurgents challenge, but remain in control of all major population centers. Hence, we classify the Free Syrian Army as military weaker relative to the government and with only minimal external support. In sum, we believe that our classification of the covariates for the Syria conflict demonstrates that the core covariates emphasized in our model are ex ante observable characteristics known to the parties and identifiable by outsiders.

\section{Insert Table 1 About Here}

\section{In-Sample Results}

We first briefly discuss the in-sample estimates of our model before turning to the out-ofsample predictions. Table 2 reports the selection and outcome estimates generated using all observations from 1946-1992. The estimated coefficients are largely in line with 
expectations; Territorial, high intensity, and post-cold war conflicts are more susceptible to mediation. Higher relative rebel strength makes mediation more likely. Past conflict management, in particular previous successes, foster subsequent mediation, while parallel conflicts in a state and longer conflict duration make mediation less likely.

The results are less conclusive in the outcome equation. Territorial incompatibilities and high intensity conflict appear to make positive outcomes more likely, but the estimated coefficients are not significantly different from 0 . Parallel conflict has a negative sign and remains highly significant. The only factor changing direction from the incidence to outcome results is conflict duration. Although an increase in duration seems to decrease the likelihood of mediation, the chances of settlement seem better for mediation in longer conflicts. As expected, rebel strength and conflict management history have a significant positive effect on mediation success. ${ }^{6}$ Interestingly, previous mediation does not make future mediation more likely to succeed.

Insert Table 2 About Here

${ }^{6}$ For both the in-sample and out-of-sample analysis we also considered an alternative specification using two dummy variables for both rebel strength and conflict management history, since the relationships may not be monotonic or fully proportional for the ordinal indicator. This, however, did not yield substantially different results, and we report only the results for the simpler and more parsimonious specification. 
To assess how well the model classifies mediation and outcome in-sample we compare in Table 3 for all observations whether the predicted probabilities of mediation from the model fall above and below 0.5 and the observed outcomes. The overall results for the model at large are quite encouraging; We correctly identify 998 cases without mediation and 36 cases where mediation did occur, and the predictions generate a total of 81 false negatives and 12 false positives. In total at this threshold we see 1034 correct (92\%) and 93 incorrect predictions (8\%).

Insert Table 3 About Here

Insert Table 4 About Here

On the outcome side the classification precision is also generally high (see Table 4). 1046 actual negatives and 18 actual positives are correctly predicted, while we have 31 false negatives and 17 false positives. In total the $96 \%$ of the cases are correctly identified at the 0.5 threshold.

Out-of Sample Results 
We now turn to the implied predictions of the estimated results for the out-of-sample data, using the 1946-1992 estimates and the information on the right hand side terms for the 1993-2003 data. In Table 5, we compare the observed outcomes (rows) with the predictions of the model for mediation (P1, in columns), dichotomized based on whether the predicted probabilities are above or below 0.5, i.e. whether mediation is predicted as more likely to occur than not. At this threshold we correctly identify 287 conflict years where we do not see mediation, as well as 63 of the cases where mediation did occur. We miss 51 actual instances of mediation and incorrectly predict mediation in 16 cases where it ultimately did not occur. Overall, about $84 \%$ of the observations are correctly classified in terms of whether we see mediation or not.

\section{Insert Table 5 About Here}

To evaluate the predictions about mediation success we need to take into account the twostage nature of the model. A natural way to consider predictions about mediation success here is by examining the predictions for cases where we expect mediation to occur (i.e., $\mathrm{P} 1>0.5)$ and then consider whether the predicted success for these cases (P2) exceed 0.5, conditional on mediation occurring. Table 6 reports the predicted values for P2 against the observed outcomes. ${ }^{7}$ At this threshold we correctly identify 38 cases of successful mediation, 287 cases where mediation was not attempted and deemed unlikely to be successful, and 20 cases where we correctly predicted an unsuccessful episode of

\footnotetext{
${ }^{7}$ We provide tables for all the observations ordered by the predicted values $\mathrm{P} 1$ and $\mathrm{P} 2$ and the observed outcomes in the online appendix.
} 
mediation. We incorrectly predict 41 cases of successful mediation (16 cases where mediation did not occur and 25 where mediation failed), and we miss 23 successful cases of mediation where we did not expect mediation to occur. Overall, $84 \%$ of the observations are correctly predicted based on the model in terms of predicted versus observed success.

\section{Insert Table 6 About Here}

To consider the value of the two stage approach we can compare the implied predictions to a one equation for success, using the same predictors. The single equation model correctly predicts fewer actual successful cases of mediation (35) and incorrectly predicts a larger number of false negatives (26). Overall, the two stage equation approach has a higher share of correctly predicted cases of mediation success, providing some support for the added value of a two-equation model. However, the one-stage model has a smaller number of false positives (22) and a higher number of correctly predicted unsuccessful cases (23).

Before turning to model performance and the contribution of individual covariates we briefly revisit the Syria example to show the implied predictions of the model for this case and our coding of the conflict characteristics. Based on the values in Table 1 for the conflict at the outset and the model estimates in Table 2 we find a low initial likelihood of mediation of only 0.11 in 2011 . The conditional probability of success if mediation occurs is below average but still relatively high (0.50), although given the low likelihood of mediation the predicted probability of success conditional on mediation occurring is of limited relevance. Our low predicted likelihood of seeing mediation in Syria seems to 
reasonably reflect the unfavorable conditions for mediation to be acceptable to the parties. Although our estimates suggest that mediation is unlikely, one might argue that the salience of this conflict may have contributed to more international efforts to mediate than perhaps warranted by the prospects for success, and various mediation teams have been active within the Syrian conflict (Aljazeera, 2013). The covariates also suggests that future mediation efforts make new efforts more likely, even if the initial efforts fail.

\section{Analysis of model performance and covariate contributions}

Since any division of the data into the classification and evaluation sample could be deemed as arbitrary, we conduct a 4-fold analysis where we partition the data into four randomly selected segments. We consider all possible combinations of the four partitions, using three of the data partitions to estimate the model while leaving aside the fourth partition for an out-of-sample assessment (see Effron 1983; Ward et al. 2010). Since the results could depend on the initial partition we repeat the 4-fold analysis for 10 different partitions. In general, the results for the overall classification remain robust; on average our model correctly forecasts mediation onset in $89 \%$ of cases and correctly predicts mediation outcome in approximately $92 \%$ of the conflict years.

Instead of focusing on a single binary threshold a receiver operating characteristic or ROC plot allows us to compare the discriminatory ability of the model across a range of prediction thresholds. This method compares the share of correctly predicted $0 \mathrm{~s}$ and $1 \mathrm{~s}$ for each possible threshold as a curve. A random guess based on the sample proportions would fall around the 45-degree line, while models with better predictive power should be closer to the top left corner. The left panel in Figure 1 displays the ROC plot for mediation incidence in the out-of-sample results. The considerable gap between the curve and the 45 
degree line indicates that model provide a great deal of information to predict mediation incidence over a random guess.

Greenhill, Ward and Sacks (2011) have suggested separation plots as a way to visually inspect the predictive power of binary response models. A separation plot arranges the individual observations by their predicted values for the event of interest from left to right, with a solid line indicating the predicted probability for each event, and adds dark and light vertical lines or shades based on the observed response. For a model that fits well, we should see a separation plot where all the observed events (with dark shades) are clustered at the right and all the non-events (with light panels) cluster at the left. The right panel in Figure 1 presents a separation plot for mediation out-of-sample. As can be seen, the cases with the highest predicted probabilities of mediation at the right end do indeed generally correspond with actual mediation. Likewise, although we do have some cases of actual mediation in cases where the model indicates that mediation would be unlikely toward the left of the plot, the overall ability of the model to separate instances of mediation and cases without mediation seems encouraging. 


\section{Insert Figure 1 About Here}

Evaluating the predictions for mediation success is more complex, since we now need to consider two different prediction thresholds. In Figure 2 we display in the left panel the ROC plot at different thresholds for P2, conditional on mediation for cases with a predicted probability of mediation exceeding the probability of not seeing mediation (i.e., P1>0.5). Again, the ROC curve for the model is well above the 45 degree line, although less so than for mediation onset. As such, it does appear as if the model picks up on structural factors that are informative predictors of success out-of-sample and that the insample fit does not just reflect idiosyncrasies of data. In the right plot of Figure 2 we display the separation plots for predicted mediation success, conditional on the predicted probability of mediation exceeding 0.5 . In general, we see more black bars indicating actual successful instances of mediation towards the right side of the plot where the individual observations have higher predictive values, and fewer towards the cases deemed unlikely towards the left side of the plot. In sum, we interpret this as evidence of reasonably good out-sample discriminative ability of the model overall for mediation success.

\section{Insert Figure 2 About Here}


The ROC and separation plots tell us something about the overall ability of the model to identify outcomes out-of-sample. However, these measures all reflect the overall predictions of the model, and do not provide information about the contribution of individual features to the predictive power of the model or what does the heavy lifting in shifting predictions. For a measure of the impact of the contribution of individual covariates, Ward et al. (2010) propose looking at the change in the so-called area under the curve (AUC) in a ROC plot when a covariate is omitted from a model. In this case, the AUC for the full model for the prediction of mediation onset for the 1993-2003 is 0.849 . We then look at how the resulting AUC for the model for the two outcomes when each of the covariates is dropped. We report in Table 7 the results for individual covariates for mediation outcome. As can be seen, the greatest changes in the AUC are found when omitting the terms for 'Territorial Incompatibilities' and 'Parallel Conflict', indicating that these terms make the most notable contributions to increasing the predictive power. Obviously, the changes in AUC can be sample dependent, but across our k-fold analysis we consistently found territorial incompatibilities and parallel ongoing conflicts had the greatest impact on predictive power. For the other covariates the change in the AUC when a term is omitted is much smaller, indicating a much more limited contribution to the predictive ability of the model out of sample. Most dramatically, we actually find that the AUC slightly increases when we omit the conflict intensity and previous mediation terms from the model. Over our k-fold analysis, however, we found on average that all the terms increased the AUC when included.

\section{Insert Table 7 About Here}


For the model predictions of mediation success in the 1993-2003 sample the AUC for the full model is 0.723 , reflecting how we generally seem to do better at identifying where mediation is likely than the outcome of mediation, if applied. However, when we inspect the change in the AUC for mediation outcome from dropping individual terms from the model in Table 8, we here find that none of the individual features seem to provide positive contributions at all. Indeed, the AUC in all cases actually increases when individual terms are dropped, although less so for parallel conflicts and territorial incompatibilities. Thus, although our results seem relatively encouraging for the model overall, it is hard to attribute much out-of-sample predictive power to any single individual term for mediation success.

\section{Insert Table 8 About Here}

These results call for an explanation for the seeming puzzle of why the conventional model seems to do relatively well in identifying when mediation is likely to occur but much less well in determining the outcome of mediation. One possible interpretation is that the covariates considered here are generally structural features that shape the costs that belligerents incur from ongoing violence. These characteristics, which are observable to the actors in advance of mediation, are likely to shape the willingness of third parties to offer mediation as well as the willingness of conflict antagonists to accept such assistance. The features that shape belligerents willingness to accept mediation are probably related to their expectations about mediation success. However, these structural features themselves are not sufficiently informative to allow us to predict the eventual outcome of the process. Even if structural factors indicate the propensity for a settlement 
and may serve to rule out mediation in some unlikely cases, favorable conditions are by themselves no guarantee for success.

Unobservable features are likely to loom much larger for mediation outcome, which depends on the extent to which mediation manages to decrease uncertainty over private information held by the actors such as their intentions, reservation point, or resources and capacity to sustained prolonged conflict. For example, ex ante observable structural factors are poorly suited to distinguish cases where belligerents enter mediation with the desire to find a settlement and cases where actors accept mediation with more 'devious' intentions. Clearly a disingenuous willingness to accept mediation will be hard to detect since a 'devious' actor can only benefit if they manage to deceive others and appear to genuinely favor peace (Beardsley, 2009; Richmond, 1998). The outcome of mediation is also a function of the preferences and capabilities of the mediator leading the process. Furthermore, the resolve of the antagonists to resist a proposed settlement during mediation depends on the unobservable private preferences of leaders. For example, in Syria a peace settlement may require that Assad and his close associates leave power. Such as a move would not only threaten their power and position but potentially also their lives. It should at least in principle be possible to offer some form of sanctuary in a third country or immunity from prosecution that would be acceptable to a leader. However, such offers may suffer from a lack of credibility. Ultimately, whether offers are accepted depend on the unknown preferences of leader as well as what mediators can offer. Untangling the knot of war requires a skilled individual with sufficient knowledge, patience and flexibility to locate an agreement that exceeds the reservation point of belligerents (Brahimi and Salman, 2008). Peace agreements are often attributed to the tireless efforts of diligent mediators, such as George Mitchell, Richard Holbrooke and Lakhdar Brahimi rather than the structural conditions that facilitated the onset of a process (e.g. Curran and Sebenius, 
2003; Watkins 1999). Leaving aside the issue of whether such assessments of personal characteristics of a mediator may be exaggerated or classified based on the outcomes they purportedly explain, the specific issues done by a mediator during the course of a conflict and its likely consequences will be very difficult to forecast. The material capabilities of an intermediary, and the form of mediation that they adopt, can have a strong bearing on likelihood of settlement (Beardsley et al 2006; Bercovitch and Gartner 2006). Greater economic and military resources afford an intermediary the opportunity to adopt more active forms of mediation, using inducements that can compel a stronger actor to accept peace, or reassure a weaker party that their opponent will not renege on an agreement. Still, if these features can only be assessed once a mediator and/or mediatory strategy is known, it will be difficult to incorporate such information in out-of-sample forecasting.

In the end, we may simply need to recognize the inherent limits to our ability to make long term predictions about the outcome of mediation ex ante, beyond the structural features that make mediation a feasible prospect or not in the first place. If so, a more promising alternative approach to understanding outcomes might be to focus on a shorter time scale, and see if information revealed about ongoing mediation reflected in news can help anticipate outcomes ahead of time and the possible lead time for anticipating success or failure. Much of the variance in the covariates given prominence in mediation research is clearly across cases rather than within cases or conflicts. Looking at more disaggregated data that captures recent micro-level interactions in civil conflict can help research identify interactions between antagonists that motivate mediation and settlement and help generate better forecast of mediation success in cases such as the Syrian conflict. New real time event data projects such as the Global Database of Events, Language, and Tone (GDELT) seem a promising avenue for research along this lines (see http://gdelt.utdallas.edu). 


\section{Conclusions}

To our knowledge, this article is the first attempt to assess whether features highlighted as facilitating mediation in existing research provide some purchase on predicting when we will see mediation and likely success out-of-sample. Our results suggest that ex ante observable structural characteristics can help identify the belligerents willingness to mediate, which largely supports previous mediation research (e.g. Clayton, 2013; Greig and Regan, 2008; Svensson, 2007). In this way our results highlight a number of the key indicators that policymakers can observe to assess the likelihood of mediation in a violent conflict, and how our approach could help intermediaries to assess the prospects for mediation and allocate resources more effectively, thus illustrating the potential contribution of academic forecasting research to policy audiences. By contrast, the outcome of mediation seems to a larger extent to be influenced by characteristics that are unobservable ex ante, either in terms of private information such as the intentions of belligerents when entering mediation and the strategies, resources, or skills of the mediator.

We have already noted that forecasting mediation outcomes may require a shift from the relatively stable structural relationships between antagonists to a focus on the dynamics of the conflict once intermediaries enter and the specific proposals considered. Our findings also point to the need to identify phase shifts or significant events or changes in the relationship between actors within civil wars that can have a dramatic effect on the willingness to accept mediation. For example, many of our correct predictions of where mediation are likely are long standing conflicts where we never see mediation, including examples such as the Algeria vs. the GSPC and various low-intensity conflicts in India. However, we also have other similar protracted conflicts such as Northern Ireland, where we eventually see a turn to dialogue and mediation after a prolonged period of conflict. 
Structural characteristics collected at the annual level are unlikely to be helpful for capturing the changes and evolving conditions that open the door for mediation in such protracted conflicts.

Our results here have focused mainly on structural features that are ex ante observable, and we have argued that much of research on features relating to mediators often emphasize features that are only available ex post, and sometimes classified based on the outcomes they purportedly explain. However, the basic framework that we have advocated for predicting mediation can be extended to incorporate the likely effectiveness of certain mediators ex ante. Assessing the likelihood that different potential actors will be accepted as a mediator and their potential success can have obvious policy relevance, and greater attention to trying to forecast who mediates based on information available to the parties at the outset can overcome some of the problems associated with classifying mediator characteristics and success ex post. More generally we hope that future work will build upon the approach in this article and make prediction and out-of-sample analysis a more regular feature in the study of methods to manage and resolve violent civil conflict. 


\section{References}

Aljazeera World News. 2013. Brahimi says no Syria Peace Meeting in June available at http://www.aljazeera.com/news/europe/2013/06/201365142541855362.html, access 19.06.13.

BBC World News. 2012. Syria in Civil War: Red Cross Says available at http://www.bbc.co.uk/news/world-middle-east-18849362, accessed 21.09.12.

BBC World News. 2013. Syria Death Toll at Least 93,000 says UN available at http://www.bbc.co.uk/news/world-middle-east-22886730, accessed 17.06.13.

Beardsley, Kyle. 2011. The Mediation Dilemma. New York: Cornell University Press.

Beardsley, Kyle. 2010. Pain, Pressure, and Political Cover: Explaining Mediation Incidence Journal of Peace Research 47(4): 395-406.

Beardsley, Kyle. 2008. Agreement without Peace? International Mediation and TimeInconsistency Problems. American Journal of Political Science 52(4): 723-740.

Beardsley, Kyle. 2009. Intervention without leverage: Explaining the Prevalence of Weak Mediators. International Interactions 35(3): 272-297.

Beardsley, Kyle., David Quinn., Bidisha Biswas, and Jonathan Wilkenfeld. 2006. Mediation Style and Crisis Outcomes. Journal of Conflict Resolution 50(1): 58-86.

Bercovitch, Jacob. 2007. Mediation Success or Failure: The Search for the elusive criteria. Cardozo Journal of Conflict Resolution 7(2): 289-302.

Bercovitch, Jacob., Scott S. Gartner. 2006. Is there Method in the Madness of Mediation? Some Lessons for Mediators from Quantitative Studies of Mediation. International 
Interactions 32(4): 329-354.

Bercovitch, Jacob., Karl DeRouen. 2004. Mediation in Internationalized Ethnic Conflicts: Assessing the Determinants of a Successful Process. Armed Forces and Society 30(2): 147-170.

Bercovitch, Jacob., and Gerald Schneider. 2000. Who Mediates? The Political Economy of International Conflict Management. Journal of Peace Research 37(2): 145-165.

Bercovitch, Jacob., Paul F. Diehl, and Gary Goertz. 1997. The Management and Termination of Protracted Interstate Conflicts: Conceptual and Empirical Considerations. Millennium 26(3): 751-769.

Bercovitch, Jacob., and Richard Jackson. 2001. Negotiation or Mediation? An Exploration of Factors Affecting the Choice of Conflict Management in International Conflict. Negotiation Journal 17(1): 59-77.

Brahimi, Lakhdar., and Ahmed Salman. 2008. In Pursuit of Sustainable Peace: The Seven Deadly Sins of Mediation. New York: Center on International Cooperation.

Brandt, Patrick T., John R. Freeman and Philip A. Schrodt. 2011. Real Time, Time Series Forecasting of Inter- and Intra-state Political Conflict. Conflict Management and Peace Science 28(1): 40-63.

Bueno de Mesquita, Bruce. 2002. Predicting Politics. Columbus, OH: Ohio State University Press.

Choucri, Nazli and Thomas W. Robinson, eds. 1978. Forecasting in International Relations: Theory, Methods, Problems, Prospects. San Francisco, CA: W.H. Freeman. 
Clayton, Govinda. 2013. Relative Rebel Strength and the Onset and Outcome of Mediation in Civil War. Journal of Peace Research 50(5): Forthcoming.

Cunningham, David E. 2006. 'Veto Players and Civil War Duration' American Journal of Political Science 50(4): 875-892.

Cunningham, David E., Kristian Skrede Gleditsch, and Idean Salehyan. 2009. It Takes Two: A Dyadic Analysis of Civil War Duration and Outcome. Journal of Conflict Resolution 53(4): 570-597.

Curran, Daniel F., and James K. Sebenius. 2003. The Mediator as Coalition-Builder: George Mitchell in Northern Ireland. International Negotiation 8(1): 111-147.

De Rouen, Karl Jnr., Jacob Bercovitch \& Paulina Pospieszna. 2011. Introducing the new Civil Wars Mediation (CWM) Dataset. Journal of Peace Research 48(5): 663-672.

Dixon, William J. 1996. Third-Party Techniques for Preventing Conflict Escalation and Promoting Peaceful Settlement. International Organization 50(4): 653-681.

Efron, Bradley. 1983. Estimating the Error Rate of a Prediction Rule: Improvement on Cross-Validation. Journal of the American Statistical Association 78(382): 316331.

Fearon, James .D. 1995. Rationalist Explanations for War. International Organization 49(3): 379-414.

Gartner, Scott. S. and Jacob Bercovitch. 2006. Overcoming Obstacles to Peace: The Contributions of Mediation to Short-Lived Conflict Settlements International Studies Quarterly 50(4): 819-840.

Goldstone, Jack A., Robert H. Bates, David L. Epstein, Ted Robert Gurr, Michael B. 
Lustik, Monty G. Marshall, Jay Ulfelder and Mark Woodward. 2010. A Global Model for Forecasting Political Instability. American Journal of Political Science 54(1):190-208.

Greenhill, Brian, Michael D. Ward, and Audrey Sacks. 2011. The Separation Plot: A New Visual Method for Evaluating the Fit of Binary Models. American Journal of Political Science 55 (4):991-1002.

Greig, Michael J. 2005. Stepping into the Fray: When Do Mediators Mediate? American Journal of Political Science 49(2): 249-266.

Greig, Michael J, and Patrick Regan. 2008. When Do They Say Yes? An Analysis of the Willingness to Offer and Accept Mediation in Civil Wars. International Studies Quarterly 52(4): 759-781.

Greig, Michael J \& Paul Diehl. 2006. Softening Up: Making Conflicts More Amenable to Diplomacy. International Interactions 32(4): 355-384.

International Business Times. 2012. UK Recognizes Syrian Opposition Leadership. Available at http://www.ibtimes.com/uk-recognizes-syrian-opposition-415952, accessed 21.09.12.

Jackson, Richard. 2000. Successful Negotiation in International Violent Conflict. Journal of Peace Research 37(3): 323-343.

Kreutz, Joakim. 2010. How and When Armed Conflicts End: Introducing the UCDP Conflict Termination Dataset. Journal of Peace Research 47(2): 243-250.

Lacina, Bethany \& Nils Petter Gleditsch. 2005. Monitoring Trends in Global Combat: A New Dataset of Battle Deaths. European Journal of Population 21(2): 145-166. 
Melin, Molly M. 2011. The Impact of State Relationships on If, When, and How Conflict Management Occurs. International Studies Quarterly 55(3): 691-715.

Melin, Molly M, and Isak Svensson. 2009. Incentives for Talking: Accepting Mediation in International and Civil Wars. International Interactions 35(3): 249-271.

Morgan, Granger M., and Max Henrion. 1990. Uncertainty: A Guide to Dealing with Uncertainty in Quantitative Risk and Policy Analysis New York: Cambridge University Press.

O’Brien, Sean P. 2010. Crisis Early Warning and Decision Support: Contemporary Approaches and Thoughts on Future Research. International Studies Review 12(1):87-104.

Pruitt, Dean G., and Kenneth Kressel. 1989. Introduction: An Overview of Mediation Research. In Mediation Research: The Process and Effectiveness of Third-Party Intervention, edited by Kenneth Kressel and Dean G. Pruitt, London: Jossey-Bass.

Rauchhaus, Robert W. 2006. Asymmetric Information, Mediation, and Conflict Management. World Politics 58(2): 207-41.

Regan Patrick M., Richard Frank, and Aysegul Aydin. 2009. Diplomatic Interventions and Civil Wars: A New Dataset. Journal of Peace Research 46(1): 135-146.

Regan Patrick M. 2010. Interventions into Civil Wars: A Retrospective Survey with Prospective Ideas. Civil Wars 12(4): 456-476.

Reuters. 2012. Syrian Death Toll now Tops 30,000: Syrian Activist Group. Available at http://www.reuters.com/article/2012/09/26/us-syria-crisis-tollidUSBRE88P12Y20120926, accessed 11.10.12. 
Richmond, Oliver. 1998. Devious objectives and the disputants' view of international mediation: A theoretical framework Journal of Peace Research 35(6): 707-722.

Rustad, Siri C. Å., Halvard Buhaug, Åshild Falch and Scott Gates. 2011. All Conflict is Local: Modeling Sub-National Variation in Civil Conflict Risk. Conflict Management and Peace Science 28(1): 15-40.

Sartori, Anne E. 2003. An Estimator for Some Binary Outcome Selection Models Without Exclusion Restrictions. Political Analysis 11(2): 111-138.

Schneider, Gerald; Nils Petter Gleditsch \& Sabine C. Carey. 2011. Forecasting in International Relations: One Quest, Three Approaches. Conflict Management and Peace Science 28(1): 5-14.

Singer, J. David and Michael David Wallace. 1979. To Augur Well: Early Warning Indicators in World Politics. Beverly Hills, CA: Sage.

Skjelsbæk, Kjell. 1991. The UN Secretary-General and the Mediation of International Disputes. Journal of Peace Research 28(1): 99-115.

Slantchev, Branislav L. 2003. The Principle of Convergence in Wartime Negotiations. American Political Science Review 97(4): 621-632.

Svensson, Isak. 2007. Bargaining, Bias and Peace Brokers: How Rebels Commit to Peace. Journal of Peace Research 44(2): 114-163.

Svensson, Isak. 2009. Who Brings Which Peace: Biased versus Neutral Mediation and Institutional Peace Arrangements in Civil Wars. Journal of Conflict Resolution 53:3: $446-469$.

Tetlock, Philip. 2005. Expert Political Judgment: How Good is it? How Can we Know? 
Princeton, NJ: Princeton University Press.

Touval, Saadia., and William Zartman I. 1985. International Mediation in Theory and Practice. Boulder, CO: Westview Press.

Watkins, Michael. 1999. Getting to Dayton: Negotiating an End to the War in Bosnia. HBS Case no. 1-800-134. Cambridge, MA: Harvard Business School.

Wall, James A., John B. Stark, and Retta L. Standifer. 2001. Mediation: A Current Review and Theory Development. Journal of Conflict Resolution 45(3): 370-391.

Wall, James A., and Ann Lynn. 1993. Mediation: A Current Review. Journal of Conflict Resolution 37(1): 160-194.

Walter, Barbara. 2003. Explaining the intractability of territorial conflict. International Studies Review 5(4): 137-153.

Walter, Barbara. 1997. The Critical Barrier to Civil War Settlement. International Organization 51(3): 335-364.

Ward, Michael D., Brian D. Greenhill and Kristin M. Bakke. 2010. The Perils of Policy by p-value: Predicting Civil Conflicts. Journal of Peace Research 47(4): 363-375.

Weidmann, Nils, Jan Ketil Rød and Lars-Erik Cederman. 2010. Representing Ethnic Groups in Space: A New Dataset. Journal of Peace Research 47(4): 491-499.

Wilkenfeld, Jonathan., Kathleen Young., David Quinn and Victor Asal. 2005. Mediating International Crises. London: Routledge.

Zartman, William I., 1993. The Unfinished Agenda: Negotiating Internal Conflicts. In: Roy Licklider, ed, Stopping the Killing: How Civil Wars End. New York, London: New York University Press. 
Table 1: Covariates for the Syrian Conflict at the Start of the Conflict

\begin{tabular}{|l|c|}
\hline Variable & Value \\
\hline Conflict intensity & Low \\
\hline Conflict duration & 0 Years \\
\hline Incompatibility & Government \\
\hline Parallel Conflict & No \\
\hline Post-Cold War & Yes \\
\hline Relative rebel strength & Weaker \\
\hline Mediation previous year & No \\
\hline Outcome of mediation in previous year & No Mediation \\
\hline
\end{tabular}


Table 2: Estimated Mediation Onset and Outcome Result for Training Sample, Sartori Estimator

\begin{tabular}{|c|c|c|}
\hline & (1) & (1) \\
\hline & Selection & Outcome \\
\hline Territorial incompatibility & $0.444^{* * *}(0.136)$ & $0.077(0.190)$ \\
\hline Conflict intensity & $0.136(0.148)$ & $0.293(0.238)$ \\
\hline Post-Cold War & $0.714^{* * * *}(0.141)$ & $1.063^{* * * *}(0.187)$ \\
\hline Another conflict ongoing in state/year & $-0.530^{* * * *}(0.153)$ & $-0.516^{* * *}(0.227)$ \\
\hline Conflict duration & $-0.007(0.007)$ & $0.001(0.009)$ \\
\hline Relative rebel strength & $0.372^{* * *}(0.125)$ & $0.457^{* * * *}(0.161)$ \\
\hline Mediation previous year & $1.224^{* * *}(0.339)$ & $1.216^{* * * *}(0.358)$ \\
\hline Outcome of mediation in previous year & $0.207(0.176)$ & $0.231(0.170)$ \\
\hline Constant & $-2.324^{* * *}(0.243)$ & $-3.118^{* * * *}(0.338)$ \\
\hline Observations & \multicolumn{2}{|c|}{1112} \\
\hline Uncensored Observations & \multicolumn{2}{|c|}{110} \\
\hline Wald chi2 & \multicolumn{2}{|c|}{$152.54(8)$} \\
\hline Log psedolikelihood & \multicolumn{2}{|c|}{296.7049} \\
\hline
\end{tabular}

Significant at $* \mathrm{p}<0.10, * * \mathrm{p}<0.05, * * * \mathrm{p}<0.01$ 
Table 3: In-Sample Classification of Mediation Incidence

\begin{tabular}{|l|l|l|}
\hline & $\mathrm{P}<0.5$ & $\mathrm{P}>0.5$ \\
\hline No Mediation & 998 & 12 \\
\hline Mediation & & \\
\hline & 81 & 36 \\
\hline
\end{tabular}

Table 4: In-Sample Classification of Mediation Outcome

\begin{tabular}{|l|l|l|}
\hline Table 2 & $\mathrm{P}<0.5$ & $\mathrm{P}>0.5$ \\
\hline Mediation Unsuccessful & 1046 & 17 \\
\hline Mediation Successful & 31 & 18 \\
\hline
\end{tabular}

Table 5: Out-of-Sample Predictions of Mediation Incidence

\begin{tabular}{|l|l|l|}
\hline & P1<0.5 & P1>0.5 \\
\hline No Mediation & 287 & 16 \\
\hline Mediation & 51 & 63 \\
\hline
\end{tabular}


Table 6: Out-of-Sample Predictions of Mediation Outcome

\begin{tabular}{|l|l|l|}
\hline & P2<0.5 & P2>0.5 \\
\hline No Mediation & 287 & 16 \\
\hline Mediation & 20 & 25 \\
\hline Unsuccessful & & \\
\hline Successful & & 38 \\
\hline
\end{tabular}


Table 7: Out-of-Sample Predictions of Mediation Onset

\begin{tabular}{llr} 
Variable excluded & AUC & \multicolumn{1}{c}{$\Delta$ AUC } \\
Conflict Intensity & 0.8559 & -0.0074 \\
Mediation Last Year & 0.8522 & -0.0037 \\
Post Cold War & 0.8474 & 0.0011 \\
Duration & 0.8466 & 0.0019 \\
Outcome Last Year & 0.8462 & 0.0023 \\
Rebel strength & 0.8429 & 0.0056 \\
Parallel Conflict & 0.8152 & 0.0333 \\
Territorial Conflict & 0.8146 & 0.0339
\end{tabular}

Table 8: Out-of-Sample Predictions of Mediation Success

$\begin{array}{lll}\text { Variable excluded } & \text { AUC } & \Delta \text { AUC } \\ \text { Mediation Last Year } & 0.8343 & -0.111 \\ \text { Duration } & 0.8178 & -0.095 \\ \text { Post Cold War } & 0.8159 & -0.093 \\ \text { Conflict Intensity } & 0.8057 & -0.083 \\ \text { Outcome Last Year } & 0.8048 & -0.082 \\ \text { Rebel Strength } & 0.8007 & -0.078 \\ \text { Parallel Conflict } & 0.7989 & -0.076 \\ \text { Territorial Conflict } & 0.7799 & -0.057\end{array}$


Figure 1: ROC and separation plots, predicted mediation, 1993-2003 data, based on Table 1 estimates
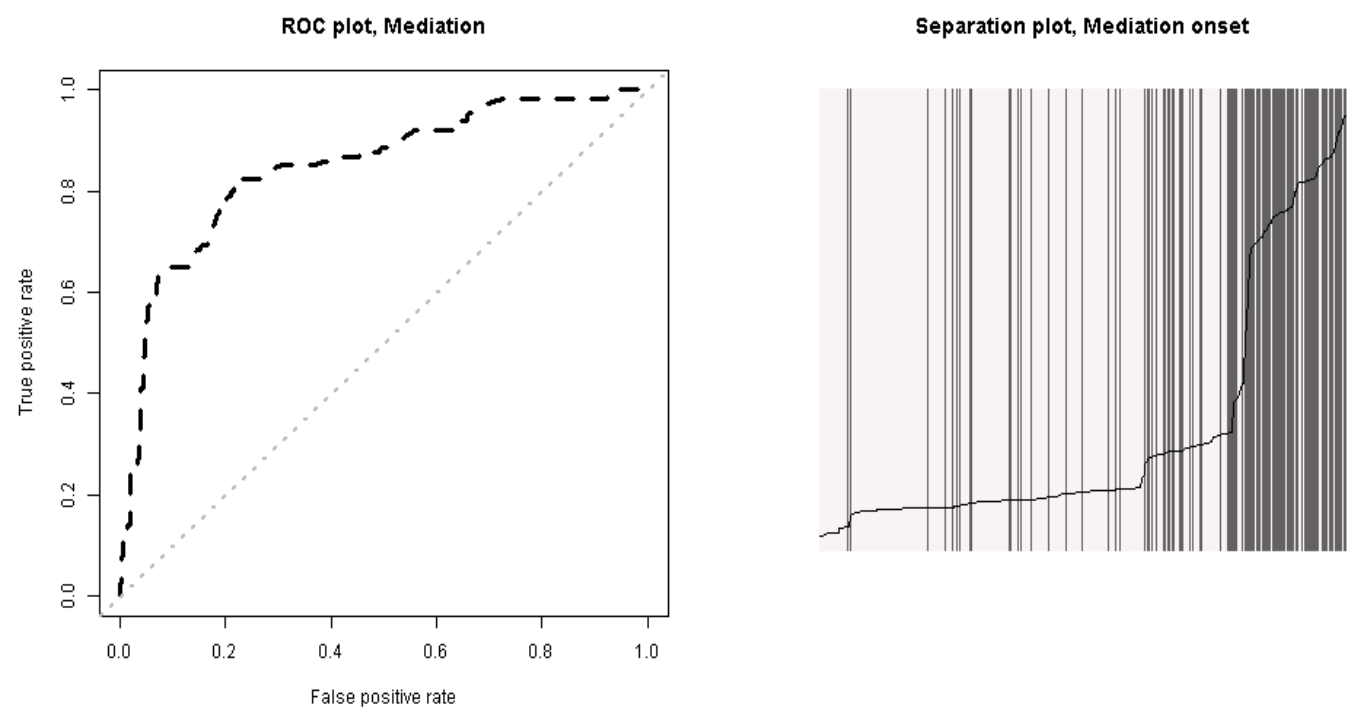
Figure 2: ROC and separation plots, predicted mediation success (conditional on mediation, if P1>0.5), 1993-2003 data, based on the Table 1 estimates.
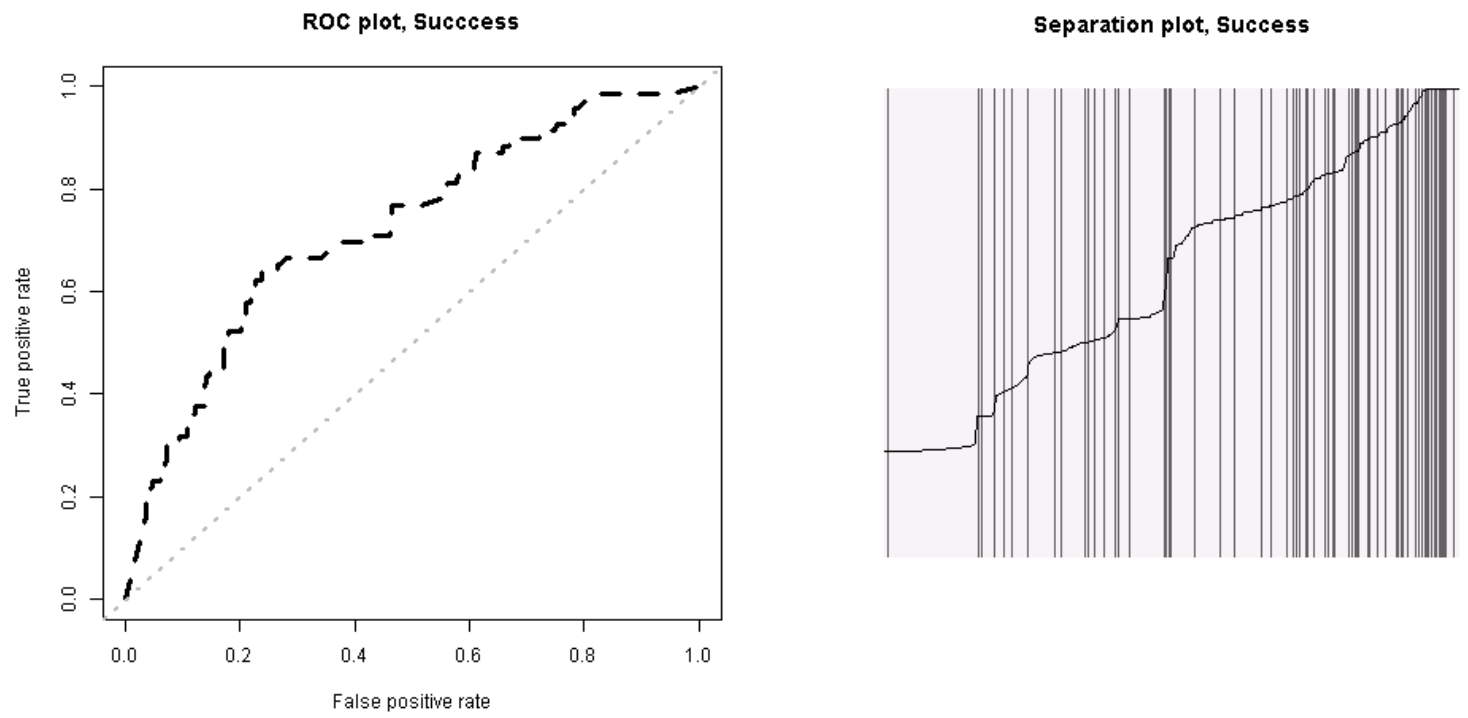